\title{
H-Bonding Controls the Regio-selectivities on the Acid-catalyzed Reaction of Fluorenone with Phenol Derivatives
}

\author{
Gyoosoon Park, Eun Mook Park, ${ }^{\dagger}$ and Choon Sup Ra ${ }^{\dagger, *}$ \\ Department of Bio and Nano Chemistry, Kookmin University, Seoul 136-702, Korea. ${ }^{*}$ E-mail: gpark@kookmin.ac.kr \\ ${ }^{\dagger}$ Department of Chemistry and Institute of Natural Science, Yeungnam University, Gyongsan 712-749, Korea \\ *E-mail:csra@yu.ac.kr \\ Received April 6, 2010, Accepted May 19, 2010
}

Key Words: Fluorenone, Phenol derivatives, Electrophilic aromatic substitution, Regio-selectivity, H-bonding

Electrophilic substitution reaction is the most widely used procedure for introducing functional groups to the aromatic ring. Activated electrophiles containing carbonyl functions such as aldehydes and acyl halides are added smoothly to phenol and its derivatives under catalytic condition. However, it is rare the reaction of carbonyl compounds like ketones with aromatic rings to form a carbon-carbon bond, and to be considered unusual due to the unfavorable equilibrium. ${ }^{1}$ A recent paper reported this unusual carbonyl functionalization (Scheme 1), ${ }^{2,3}$ where fluorenone under acidic condition is reacted with activated aromatic compounds (phenols) to produce spiro[fluorene-9,9'xanthene](SFX) and related compounds. The overall reaction is highly regio-selective. Those remarkable features of this reaction prompt us to study the usefulness of the reaction and identify the regio-control elements in the process.

We understand the reaction path involves an electrophilic attack of C9 of fluoren-9-one to phenol in the presence of proton. Regarding the ortho- vs. para- selectivity, we have considered the electrophilic attack of fluoren-9-one to phenol and its derivatives in the presence of proton. To understand the reaction path in detail, we have investigated the optimized chemical species involved in the reaction as shown in Scheme 2.

All ab initio calculations have been carried out using the Gaussian 98 program. ${ }^{4}$ The structures of the intermediates and transition states were then fully optimized using the density functional theory B3LYP/6-31G(d). ${ }^{5}$ Harmonic vibrational frequencies calculated at the same level were used for the characterization of stationary points. The number of imaginary fre-

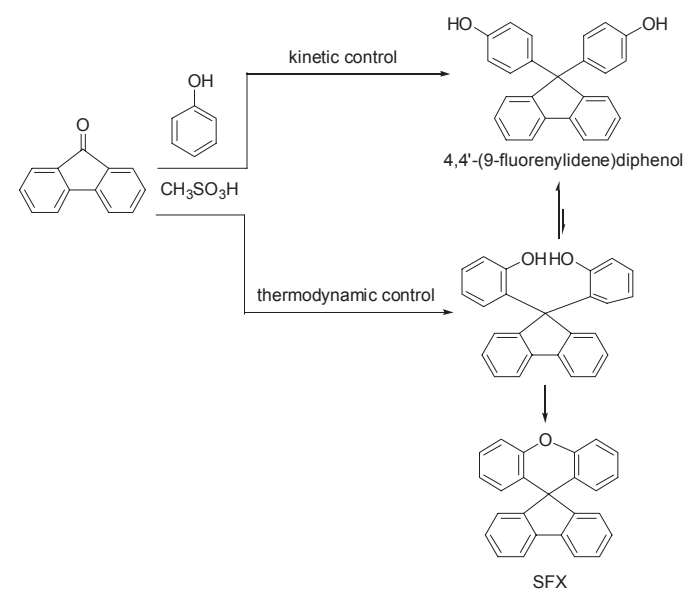

Scheme 1 quencies $(0$ or 1$)$ indicates whether a minimum or a transition state has been located.

Table 1 shows optimized energies of phenol and its derivatives as well as transition states and products of the reaction in orthoand para-approach. ${ }^{6}$ For the reaction with phenol, the activation energies are predicted by $10.38 \mathrm{kcal} / \mathrm{mol}$ for para-attack and $9.79 \mathrm{kcal} / \mathrm{mol}$ for ortho-attack, respectively. According to the relative TS energies for reaction of phenol to fluorenone, the ortho-approach is slightly favorable path than para-approach of phenol by $0.59 \mathrm{kcal} /$ mole (entry $1 \& 2$ in Table 1 ). According to Mulliken charge density, ${ }^{6}$ one may anticipate the orthoapproach may be electronically favorable over para-approach. In contrast, the reaction of toluene to fluorenone is predicted by opposite fashion. The para-attack appears more favorable than the ortho-approach by $2.99 \mathrm{kcal} / \mathrm{mole}$ (entry $3 \& 4$ in Table 1 ). The difference of energy is substantially large. One may attribute the disfavorable ortho-approach to a possible steric effect of methyl group.

Figure 1 illustrates two stable TSs for each reaction of phenol and toluene, respectively. It is noted the distance of $\mathrm{O} 9{ }^{\cdots} \cdot \mathrm{H} 1^{\prime}$ show $2.123 \AA$ in the optimized transition state TS-o-OH, which is called up hydrogen bonding ${ }^{7}$ between phenol and fluorenone. The energy difference in products is substantial. Energetically PD-o-OH is more stable than PD-p-OH by $5.85 \mathrm{kcal} / \mathrm{mol}$, which obviously attributes to an intra-molecular hydrogen bonding. In the optimized structure PD-o-OH, the distance of $\mathrm{O} 9{ }^{-\cdots} \mathrm{H}^{\prime}{ }^{\prime}$ shows $1.761 \AA$, which is shorter than the distance in TS-o-OH. ${ }^{8}$

As the hydrogen bonding is regarded to be an important factor for the preference of ortho-approach for the reaction of phenol,

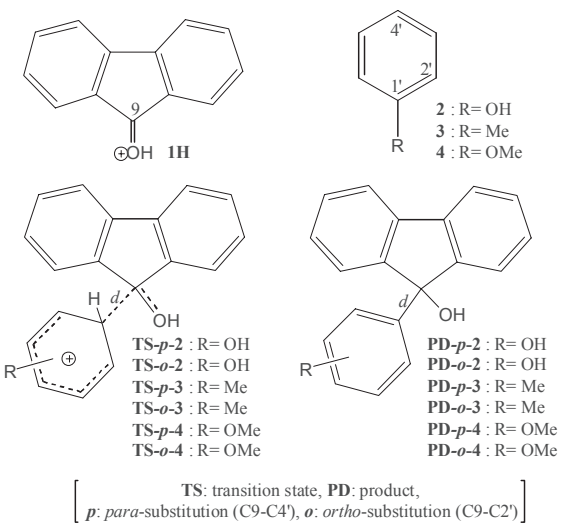

Scheme 2 
Table 1. The calculation results for the optimized transition states and products

\begin{tabular}{|c|c|c|c|c|c|c|c|}
\hline \multirow{2}{*}{ no } & \multirow{2}{*}{ compounds } & \multicolumn{4}{|c|}{ B3LYP/6-31G*//B3LYP/6-31G* } & \multicolumn{2}{|c|}{ MP2/6-31G*//B3LYP/6-31G* } \\
\hline & & $\mathrm{E}_{\text {tot }}{ }^{a}$ & $\mathrm{E}_{a c t}^{b}\left(\mathrm{E}_{r e l}^{c}\right)$ & & & $\mathrm{E}_{\text {tot }}{ }^{a}$ & $\mathrm{E}_{\text {rel }}^{c}$ \\
\hline 1 & TS-p-OH & -883.2347805 & $10.383(0.595)$ & 1.858 & & -880.4719719 & 1.215 \\
\hline 2 & TS-o-OH & -883.2357293 & $9.788(0.000)$ & 1.946 & $2.123^{e}$ & -880.4739076 & 0.000 \\
\hline 3 & TS-p-Me & -847.3269977 & $16.368(0.000)$ & 1.732 & & -844.5986273 & 0.000 \\
\hline 4 & TS-o-Me & -847.3222300 & $19.360(2.992)$ & 1.725 & & -844.5961797 & 1.536 \\
\hline 5 & TS-p-OMe & -922.5449320 & $8.063(0.000)$ & 1.905 & & -919.6310809 & 0.000 \\
\hline 6 & TS-o-OMe $e^{f}$ & -922.5406961 & $10.721(2.658)$ & 1.72 & & -919.6277173 & 2.111 \\
\hline 7 & PD-p-OH & -882.8935280 & $(5.846)$ & 1.532 & & -880.1440208 & 6.696 \\
\hline 8 & PD-o-OH & -882.9028435 & $(0.000)$ & 1.530 & $1.761^{e}$ & -880.1546911 & 0.000 \\
\hline 9 & PD-p-Me & -846.9954227 & $(0.000)$ & 1.533 & & -844.2816833 & 0.000 \\
\hline 10 & PD-o-Me & -846.9890322 & $(4.010)$ & 1.537 & & -844.2775869 & 2.570 \\
\hline 11 & PD-p-OMe & -922.2000558 & $(0.000)$ & 1.532 & & -919.2988029 & 0.000 \\
\hline 12 & PD-o-OMe & -922.1930199 & (4.415) & 1.539 & & -919.2936513 & 3.233 \\
\hline
\end{tabular}

${ }^{a} \mathrm{E}_{\text {tot }}$, total energy (a.u.) at b3lyp/6-31 $\mathrm{G}^{*} / \mathrm{b} 3 \mathrm{lyp} / 6-31 \mathrm{G}^{*}$ and $\mathrm{mp} 2 / 6-31 \mathrm{G}^{*} / / \mathrm{b} 31 \mathrm{yp} / 6-31 \mathrm{G}^{*} \cdot{ }^{b} \mathrm{E}_{a c t}$, activation energies $(\mathrm{kcal} / \mathrm{mol})$ are based upon the data from $\mathrm{b} 3 \mathrm{lyp} / 6-31 \mathrm{G} * / / \mathrm{b} 31 \mathrm{yp} / 6-31 \mathrm{G} *$ method, which are derived from $\mathrm{E}_{t o t}(\mathbf{1 H}+\mathbf{2}), \mathrm{E}_{t o t}(\mathbf{1} \mathbf{H}+\mathbf{3})$ and $\mathrm{E}_{t o t}(\mathbf{1} \mathbf{H}+\mathbf{4})$, where the total energies $(\mathrm{a} . \mathrm{u}$.) are -575.7864605 for $\mathbf{1 H},-307.4648665$ for $\mathbf{2},-271.5666211$ for $\mathbf{3}$ and -346.7713204 for $\mathbf{4}$. ${ }^{c} \mathrm{E}_{\text {rel }}$, relative energies (kcal/mol) show relative stability between TS-o vs. TS- $\boldsymbol{p}$ or PD-o $v s$. PD- $\boldsymbol{p}$. ${ }^{d}$ The distance ( $\AA$ ) $d$ shows length of C9-C2' (for ortho-attack) and C9-C4' (for para-attack) in TS or PD. 'Distance of O9-H1' in TS-o-OH and PD-o-OH. The optimized TS-o-OMe is deduced from scanning with increment of $d(\mathrm{C} 9-\mathrm{C} 2$ ') by $0.01 \AA \AA$.
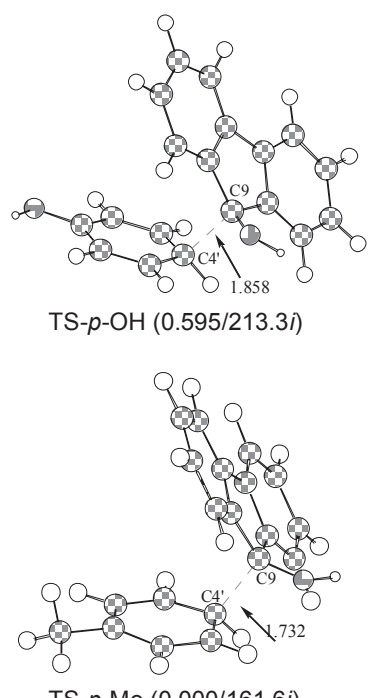

TS-p-Me $(0.000 / 161.6 i)$
TS-p-OH $(0.595 / 213.3 i)$

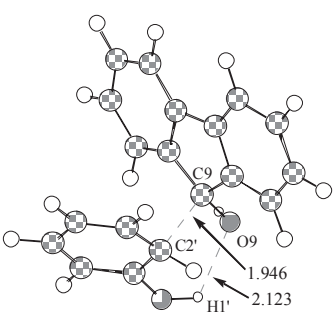

TS- $p-\mathrm{OH}(0.000 / 333.3 i)$

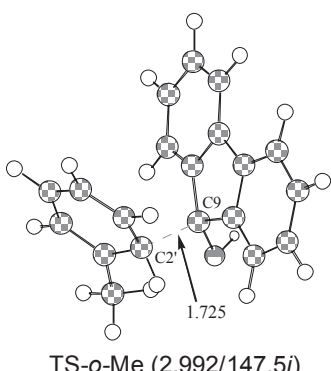

TS-o-Me $(2.992 / 147.5 i)$
Figure 1. Geometries of four TSs, TS-p-OH, TS-o-OH, TS- $p$-Me and TS-o-Me, optimized at the B3LYP/6-31G(d). The values in parenthesis are relative energy values $(\mathrm{kcal} / \mathrm{mol})$ calculated at the B3LYP/ 6-31G(d)//B3LYP/6-31G(d) levels and the imaginary frequency.

the para-approach might be a dominant path without a hydrogen bonding in ortho-approach. For the reaction with anisole, the optimized energy of TS-p-OMe shows lower than TS-o-OMe by $2.66 \mathrm{kcal} / \mathrm{mol}$, which is similar to toluene reaction system (see entry 3-6 in Table 1). According to the relative stability of products from the toluene and anisole, the preference of parasubstitution is predicted by 4.01 and $4.40 \mathrm{kcal} / \mathrm{mole}$, respectively (entry 9-12 in Table 1), which is contrary to the phenol system as discussed above. Such the trend between ortho- and para-substitution is in accord with $\mathrm{mp} 2 / 6-31 \mathrm{G}^{*}$ energies at the optimized geometries with B3LYP/6-31G* as shown in Table 1. The above calculation results all agree with our prospect. We conclude the para-approach would be preferred energetically without a possible hydrogen bonding for the transition states as well as the products.

For parallel experimental studies to verify, we have performed the reaction of anisole to fluorenone, where the hydrogen bonding is not available. ${ }^{9}$ The reaction at $140{ }^{\circ} \mathrm{C}$ in the presence of methanesulfonic acid gave only the para-adduct 9,9-bis-(4methoxy-phenyl)- $9 H$-fluorene (32\% yields in $24 \mathrm{~h}$ ). In the case of the reaction of phenol with fluorenone, two products are obtained in $88 \%$ yields corresponding to via para- and orthoadduct. The product ratio of spiro[fluorene-9,9'-xanthene] (SFX) to 4,4'-(9-fluorenylidene)diphenol increases with reaction time (23:77 at 3 h, 49:51 at $6 \mathrm{~h}$, and 60:40 at $24 \mathrm{~h}$ ). It suggests the ortho-adduct is thermodynamically more stable than paraadduct. All of experimental results are well explained by the prediction from $a b$ initio calculation studies of transition states and products. During the reaction, a possible H-bonding between phenol and fluorenone is clearly involved as well as the electron density on C-2 of phenol. Moreover the hydrogen-bonding decisively reveals in the ortho-product. Thus a relative stability of PD-o-OH attributes to intramolecular hydrogen-bonding.

Acknowledgments. This work was supported by Yeungnam University in 2008.

\section{References}

1. McMurry, J. Organic Chemistry, 7th ed.; Thomson: Belmont, CA, USA, 2008; $\mathrm{p} 707$.

2. Xie, L.-H.; Liu, F.; Tang, C.; Hou, X.-Y.; Hua, Y.-R.; Fan, Q.-L.; Huang, W. Org. Lett. 2006, 8, 2787.

3. (a) Morgan, P. W. Macromolecules 1970, 3, 536. (b) Chou, C.-H.; Shu, C.-F. Macromolecules 2002, 35, 9673.

4. Gaussian 98 Revision A.7, Gaussian, Inc.: Pittsburgh, PA, 1998.

5. (a) Becke, A. D. J. Chem. Phys. 1993, 98, 5648. (b) Lee, C.; Yang, W.; Parr, R. G. Phys. Rev. B 1988, 37, 785.

6. For the atomic charge of phenol derivatives (B3LYP/6-31G*), ortho-position show larger than para-position: the Mulliken atomic charges of ortho/para center show $-0.194 /-0.135$ for phenol, $-0.182 /$ -0.133 for toluene, $-0.196 /-0.134$ for anisole.

7. For a review on hydrogen bond, see: Steiner, T. Angew. Chem. Int. Ed. 2002, 41, 48.

8. It is noted the compound shows energetically more stabilized by increasing hydrogen bonding character. Between two optimized intermediates ortho- and para-substitution intermediate of phenol reaction, the energy difference is $6.42 \mathrm{kcal} / \mathrm{mol}$, where the distance of $\mathrm{OH} \cdots \mathrm{O}$ for intermediate of ortho-approach shows $1.626 \AA$.

9. Experimentally, it turns out the reaction of toluene to fluorenone has not been worked in various reaction conditions. Theoretically, the activation energy of the reaction of toluene to fluorenone is shown higher than that of the reaction of phenol or anisole. As shown in Table 1 , they are predicted 16.37 and $19.36 \mathrm{kcal} / \mathrm{mole}$ for para-approach and ortho-approach, respectively. 